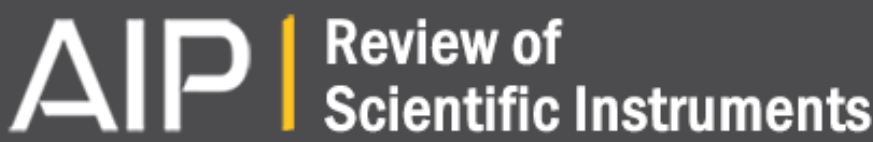

Transmission and fluorescence X-ray absorption spectroscopy cell/flow reactor for powder samples under vacuum or in reactive atmospheres

A. S. Hoffman, L. M. Debefve, A. Bendjeriou-Sedjerari, S. Ouldchikh, Simon R. Bare, J.-M. Basset, and B. C. Gates

Citation: Review of Scientific Instruments 87, 073108 (2016); doi: 10.1063/1.4958824

View online: http://dx.doi.org/10.1063/1.4958824

View Table of Contents: http://scitation.aip.org/content/aip/journal/rsi/87/7?ver=pdfcov

Published by the AIP Publishing

\section{Articles you may be interested in}

Versatile plug flow catalytic cell for in situ transmission/fluorescence x-ray absorption fine structure measurements

Rev. Sci. Instrum. 84, 054102 (2013); 10.1063/1.4807287

A spectroscopic proton-exchange membrane fuel cell test setup allowing fluorescence $x$-ray absorption spectroscopy measurements during state-of-the-art cell tests

Rev. Sci. Instrum. 82, 044101 (2011); 10.1063/1.3574225

State-Sensitive Monitoring of Active and Promoter Sites. Applications to Au/Titania and Pt-Sn/Silica Catalysts by XAFS Combined with X-Ray Fluorescence Spectrometry

AIP Conf. Proc. 882, 588 (2007); 10.1063/1.2644601

Simple flow through reaction cells for in situ transmission and fluorescence x-ray-absorption spectroscopy of heterogeneous catalysts

Rev. Sci. Instrum. 77, 023105 (2006); 10.1063/1.2168685

Bent silicon crystal in the Laue geometry to resolve x-ray fluorescence for x-ray absorption spectroscopy Rev. Sci. Instrum. 74, 4696 (2003); 10.1063/1.1618014

\section{$\oplus$ SHIMADZU Powerful, Multj-functional UV-Vis-NIR and Excellence in Science FJis Spectrophotometers}

Providing the utmost in sensitivity, accuracy and resolution for applications in materials characterization and science

- Photovoltaics

- Polymers

- Coatings

- Ceramics

- Thin films

- Inks

- Paints

Click here for accurate, cost-effective laboratory solutions
- DNA film structures

- Packaging materials

- Nanotechnology

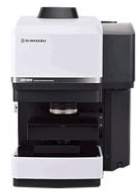

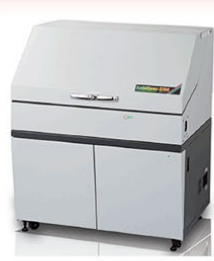




\title{
Transmission and fluorescence X-ray absorption spectroscopy cell/flow reactor for powder samples under vacuum or in reactive atmospheres
}

\author{
A. S. Hoffman, ${ }^{1}$ L. M. Debefve, ${ }^{1}$ A. Bendjeriou-Sedjerari, ${ }^{2}$ S. Ouldchikh, ${ }^{2}$ Simon R. Bare,${ }^{3}$ \\ J.-M. Basset, ${ }^{2}$ and B. C. Gates ${ }^{1, a)}$ \\ ${ }^{1}$ Department of Chemical Engineering, University of California at Davis, Davis, California 95616, USA \\ ${ }^{2}$ KAUST Catalysis Center (KCC), King Abdullah University of Science and Technology (KAUST), \\ 23955-6900 Thuwal, Saudi Arabia \\ ${ }^{3}$ SLAC National Accelerator Laboratory, SSRL, Menlo Park, California 94025, USA
}

(Received 16 March 2016; accepted 1 July 2016; published online 26 July 2016)

\begin{abstract}
$\mathrm{X}$-ray absorption spectroscopy is an element-specific technique for probing the local atomic-scale environment around an absorber atom. It is widely used to investigate the structures of liquids and solids, being especially valuable for characterization of solid-supported catalysts. Reported cell designs are limited in capabilities-to fluorescence or transmission and to static or flowing atmospheres, or to vacuum. Our goal was to design a robust and widely applicable cell for catalyst characterizations under all these conditions - to allow tracking of changes during genesis and during operation, both under vacuum and in reactive atmospheres. Herein, we report the design of such a cell and a demonstration of its operation both with a sample under dynamic vacuum and in the presence of gases flowing at temperatures up to $300^{\circ} \mathrm{C}$, showing data obtained with both fluorescence and transmission detection. The cell allows more flexibility in catalyst characterization than any reported. Published by AIP Publishing. [http://dx.doi.org/10.1063/1.4958824]
\end{abstract}

\section{INTRODUCTION}

X-ray absorption spectroscopy (XAS) is an elementspecific characterization technique for determining average local atomic-scale structure surrounding an absorbing atom. XAS is widely used to characterize liquid and solid samples including organic, inorganic, and organometallic compounds and materials ranging from single crystals to nonuniform powders. Especially important are applications of XAS for investigation of solid catalysts, which are extensively used in fuel and chemical processing. ${ }^{1}$

The X-ray absorption spectrum provides structural and chemical information characterizing the nearest-neighbor and next-near-neighbor atoms surrounding the absorber atom. Because the excitation typically requires high-energy X-rays for core shell absorption edges and benefits from high photon fluxes for detection (especially for dilute samples), most XAS measurements are made at synchrotron light sources. Synchrotrons offer the benefit of rapid scanning through a broad energy range and analysis of nearly all elements. Experiments are done by scanning through an appropriate range of photon energies while measuring the intensity of the X-ray beam upbeam and downbeam of the sample or collecting fluorescence signal perpendicular to the sample, yielding the absorption spectrum. The spectrum contains information about the near and next-near neighbors of every absorbing atom. The technique is often used to characterize nano-sized or even molecular species dispersed on the internal surfaces of porous solids. $^{2}$

\footnotetext{
a) Author to whom correspondence should be addressed. Electronic mail: bcgates@ucdavis.edu.
}

Such dispersed materials include catalysts, which typically consist of supports that are porous pellets or powders that incorporate nanoparticles of catalytically active metal, metal oxide, or metal sulfide species on their interior surfaces. Supported catalysts are widely used in petrochemical and petroleum refining technologies and are often investigated with XAS. Common supports are metal oxides (e.g., $\mathrm{Al}_{2} \mathrm{O}_{3}$, $\mathrm{SiO}_{2}, \mathrm{MgO}$ ), zeolites, carbon, and metal organic frameworks (MOFs). ${ }^{3}$

Supported catalysts are usually synthesized by reacting metal-containing precursors with support surfaces to form precatalysts, which are treated in gases to alter the metal oxidation state and/or the structures of the metal-containing species. ${ }^{4,5}$ Because many catalysts at various stages of preparation and use are reactive with $\mathrm{O}_{2}$, moisture, and/or $\mathrm{CO}_{2}$, they require handling in inert-atmosphere glove boxes and sealed sample transfer devices and XAS cells. ${ }^{6}$

Metal loadings in the range of $0.1-1.0 \mathrm{wt} . \%$ are common in industrial catalysts, ${ }^{7}$ and promoter loadings are commonly an order of magnitude lower. The ideal XAS cell for characterizing powder materials would allow measurements with samples over wide ranges of conditions, either in transmission mode for rapid data collection or in fluorescence mode for the benefit of improved elemental sensitivity. Transmission detection works well with typical supported catalysts having metal loadings of about 1 wt. \% or more, and fluorescence detection is advantageous when the metal loadings are lower, even more than an order of magnitude lower than these.

It is often advantageous to characterize a sample under vacuum (with no reactant present or adsorbed on the catalyst surface) as well as in reactive atmospheres. A key advantage of XAS is that scan times are often short enough that spectra can be recorded to track changes in catalysts as they occur 
in reactive atmospheres, even as the catalysts are functioning. To follow changes it is helpful to make measurements with gases flowing through beds of catalyst particles in cells that also serve as flow reactors, with catalytic reaction taking place as XAS measurements are made.

Characterization of stable states of catalysts is often carried out with cells designed for low-temperature (e.g., liquid nitrogen temperature) static $^{8}$ or dynamic (cryostat) vacuum operation. The sample is typically pressed into a pellet or wafer. Vacuum XAS cell designs do not allow flow of reactants or are not well suited to investigations of samples in flowing reactants because of plumbing limitations (non-flowthrough designs), large dead volumes around the sample, and the limited access of reactive molecules to the pressed samples associated with mass transfer limitations.

Early flow-through XAS cells were modifications of static sample holders and have the limitations stated above. ${ }^{8}$ Modern flow XAS cells address the issues of fluid flow and accommodate powder samples, and in some instances the flow distribution is approximated as plug flow, which is advantageous for quantifying catalyst performance based on analysis of reaction products. ${ }^{9,10}$ Typically, the meshed sample is pressed into the cell and held in the fluid flow path with glass/quartz wool. This design allows the fluid (usually gas) to pass uniformly through a bed of particles instead of around them. The reported cells in this category are smaller than static cells and are tasked for gas flow only and do not include vacuum-rated valves or seals. Modern designs of such cells include heating elements (in or around the sample compartment) and provide control of the sample temperature. Because the heating elements and the accompanying insulation are often bulky, most cells allowing heating and temperature control forgo fluorescence detection and allow operation only in transmission mode. ${ }^{10}$ The cell designed by Weiher et al., ${ }^{10}$ for example, meets most of the design criteria stated above, having the capability needed for samples under vacuum or in the presence of flowing fluids with temperature control. But it is limited to fluorescence detection and facilitates flow of reactive gases over the surface of the sample but not through a bed of particles-because the cell is designed specifically for grazing-incident XAS.

The challenge of the work reported here was to design a cell that allows characterization of reactive materials both under vacuum $\left(10^{-5}\right.$ Torr $)$ and in the presence of reactive flowing gases (e.g., $\mathrm{H}_{2}$, alkenes, alkanes, $\mathrm{CO}$ ) at rates up to $50 \mathrm{~cm}^{3} / \mathrm{min}$ at variable temperature (from room temperature to $573 \mathrm{~K}$ ) with powder samples and with fluorescence and/or transmission detection.

\section{CELL DESIGN}

The cell design reported here is based on an assessment of reported cell designs including those used recently. The cell body was modeled after designs ${ }^{9-12}$ that reduce the void volume around the sample relative to those of other designs. ${ }^{8,13-17}$ To allow fluorescence detection, the plates holding the windows in place had to be thin, as reported in previous designs, ${ }^{9-11,18}$ although not all of these are used for fluorescence detection. ${ }^{9,11,19}$ No cell has been reported to operate

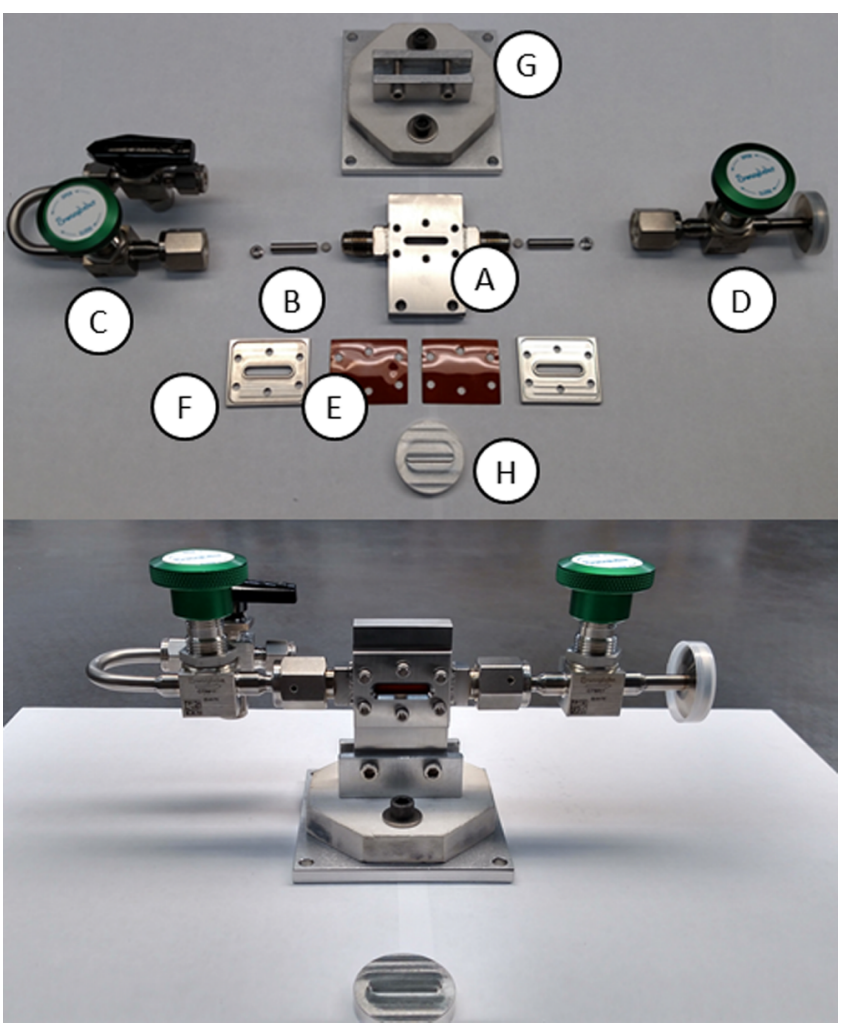

FIG. 1. Top: Unassembled XAS cell. (A) Cell body; (B) powder containment system, from left to right: hollow set screw, spacer, stainless steel fit; (C) inlet valve assembly; (D) outlet valve assembly; (E) polyimide windows; (F) window retainer plates; (G) SSRL beamline 4-1 mounting stage; $(\mathrm{H})$ sample press. Bottom: Assembled XAS cell with sample press.

well both under vacuum or gas-flow conditions. Thus, some unique design features were needed to seal the windows of the cell over a wide range of pressures while stabilizing powder samples during large pressure changes. These design features and other details are summarized below.

\section{A. Cell components}

The body of the cell is fabricated from 316 stainless steel, selected for its resistance to corrosion, high thermal stability, and thermal expansion coefficient matching those of commercial components such as fittings. The cell consists of four sections: body; inlet and outlet plumbing; windows; and stage/cell holder (Figure 1). Details of the components are summarized in Table I. Full schematics are available in the supplementary material. ${ }^{20}$ A typical cost is estimated to be in the range of $\$ 4000-\$ 6000$ per cell, depending on the number of cells being made.

\section{B. Transmission and fluorescence detection}

The X-ray beam size is a variable depending on the properties of the beamline (undulator, wiggler or bending magnet), optics (focused or unfocused), and the details of the experiment, and it is important in determining the optimum dimensions of the sample chamber. At the Stanford Synchrotron Radiation Lightsource (SSRL) at SLAC National Accelerator Laboratory beamline 4-1, for example, we use a maximum beam size of $2 \mathrm{~mm}$ (vertical, V) $\times 10 \mathrm{~mm}$ (horizontal, $\mathrm{H}$ ), for 
TABLE I. XAS cell: List of materials.

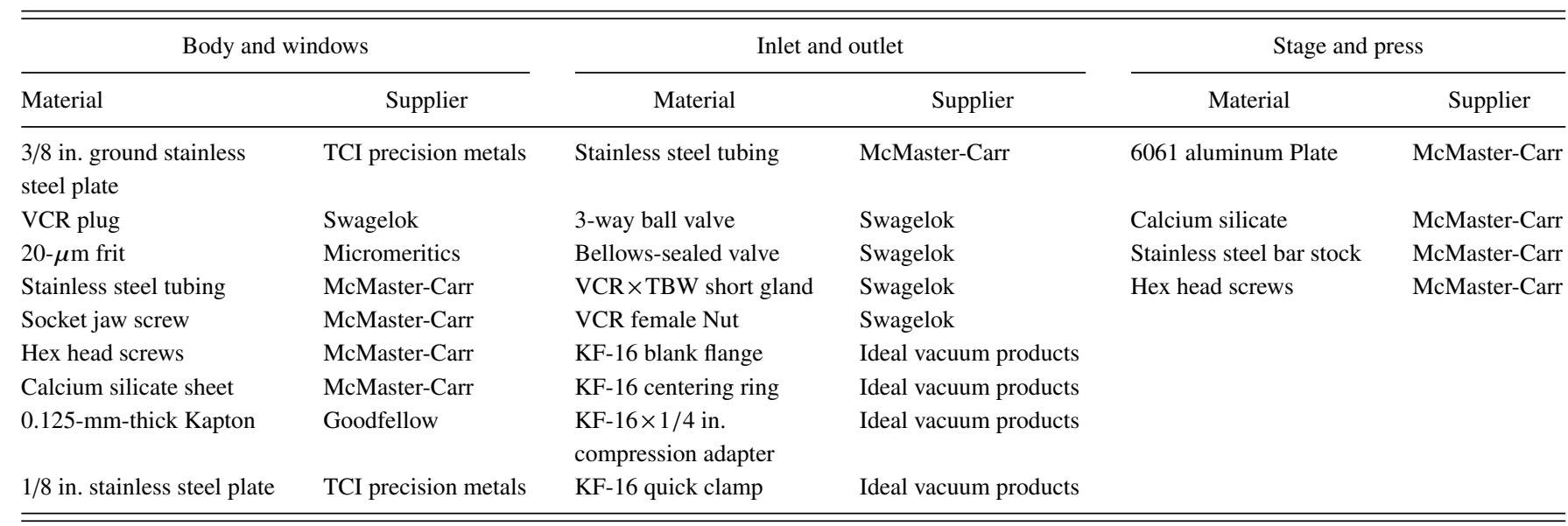

transmission and $2 \mathrm{~mm} \mathrm{~V} \times 5 \mathrm{~mm} \mathrm{H}$ for fluorescence. These dimensions were used to determine the appropriate sample area and thickness of the cell design reported here.

The XAS cell body is $3 / 8$ in. thick with $1 / 8$ in. thick window retention plates. This cell thickness allows for packing of samples like those mentioned above in order to give the typically optimal 2-3 absorption lengths for transmission detection. Catalysts with higher absorption necessitate a reduction in the overall sample mass, requiring the addition of inert, X-ray transparent particles such as boron nitride to dilute the sample. The sample cutout in the XAS cell is $4 \mathrm{~mm}$ $\mathrm{V} \times 22 \mathrm{~mm} \mathrm{H}$. This cutout, with the total cell thickness, body, and windows, is thin enough that the cell can be positioned for fluorescence detection (with a $2 \mathrm{~mm} \times 5 \mathrm{~mm}$ beam) without cutting the beam for additional transmission or reference foil spectrum collection. The cutout also allows for the identification of optimal beam placement associated with variations in the packing by giving at least $1 \mathrm{~mm}$ of movement of the cell vertically or horizontally in the beam path.

A unique feature of this cell design is the window retaining plates. Windows on controlled-atmosphere fluorescence cells are often located away from the sample and are usually much larger than windows on flow-through cells in order to reduce blocking of the fluorescence signal. The plates in our design hold the windows directly against the sample, aiding in minimizing the void volume and facilitating operation with gas flow, as summarized below. Because the windows are placed in contact with the sample, the external edges of the retaining plates around the beam path are chamfered at $45^{\circ}$ (Figure 2 ) to minimize the blocking of fluorescence signal by the plates.

\section{Operation of cell under vacuum and with gas flow}

Several key features characterize the design relating to gas flow and vacuum operation. The plumbing for flow into and out of the cell allows operation both at pressure and under high vacuum (Figure 1); details in the supplementary material ${ }^{20}$ include specifications of the corresponding valves and fittings. The plumbing is welded to reduce leaks, and minimize the size. Bellows seal valves, because of their low leak rates, are used on each side of the cell body to isolate the cell during vacuum operation. Swagelok® VCR Metal Face Seal fittings are used in sections where pressure or vacuum is required. KF flanges are used to connect the cell to a turbomolecular pump during vacuum operation, and metal compression fittings are used to connect the cell to a gas flow system. A 3-way ball valve is used in the inlet plumbing to allow for purging of the gas lines prior to introduction of gas into the cell.

The placement of the windows against the sample minimizes the gas volume around the sample and forces most of the gas through the bed of sample particles rather than around it. The passage of gas through the bed of sample optimizes gassample interaction, and the minimized volume of gas in the cell optimizes the catalyst performance characterization that can be gauged by analysis of the effluent gas, for example, by on-line gas chromatography or mass spectrometry.

The window-body interface must provide a seal under all operating conditions. Many designs take advantage of O-rings for the seals. At temperatures of about $200^{\circ} \mathrm{C}$, the O-ring seals require cooling, increasing the overall cell size, especially around the windows. The added bulk markedly blocks the fluorescence signal and largely limits high-temperature cells with

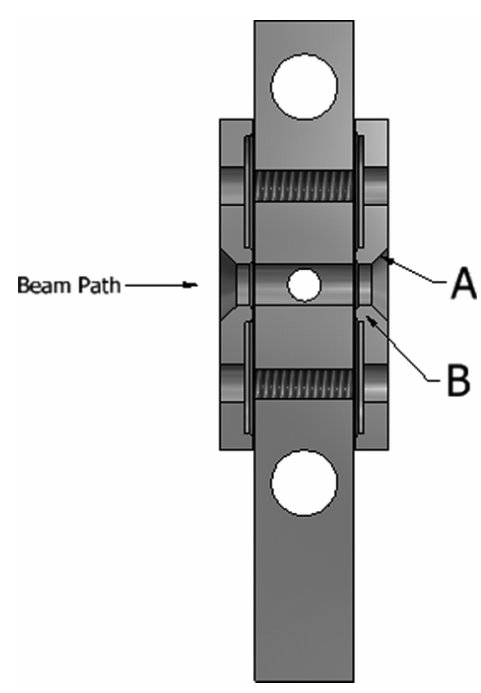

FIG. 2. Cutaway representation of the XAS cell highlighting the window holder design. (A) $45^{\circ}$ chamfer for increased solid angle for improved fluorescence signal; (B) lip around beam path and exterior edge of window for improved seal under gas flow or vacuum operation. 
O-ring seals to transmission detection. In contrast, the design presented here takes advantage of polyimide windows that are pressed between the cell body and the window retaining plate (Figure 2, B), similar to the designs of Swagelok VCR and $\mathrm{CF}$ vacuum fittings. HN Kapton is compressible, thermally stable up to $400^{\circ} \mathrm{C}$, and $\mathrm{X}$-ray transparent in the X-ray energy range applied with typical catalyst samples. Alternative window materials, such as Mylar, aluminum, or beryllium, could be used as long as the press seal does not tear through the window material.

The cell body surface requires a precision ground finish (surface roughness $=0.8 \mu \mathrm{m}$ ) with minimal imperfections to maintain the seal with the polyimide window. This design requires care in cell handling to minimize scratching. The window retaining plate is designed to have two lips on the back side (Figure 2, B) to localize the pressure, crushing the window against the body.

A design challenge is to stabilize powder samples during gas flow and during transitions between flow and vacuum operation, minimizing the sample shifting that would result in reduction of data quality. In contrast to our design, typical flow cell designs rely on glass/quartz wool packing to stabilize the samples during changes in flow conditions, and vacuum cells are not used with powder samples because the powder would be sucked out of the cell. Some vacuum cells are used with samples held in place with Kapton tape or present as pellets, being less than ideal for flow systems.

Our design uses two stainless steel $20-\mu \mathrm{m}$-pore-size frits held in place by spacers and hollow set screws (Figure 3, C-E) to confine the sample. This design creates a stationary, yet removable, packing to stabilize the sample during pressure changes. The inlet to and outlet from the sample chamber are $1 / 8$ in. in diameter, with the frits, spacers, and set screws being $3 / 16$ in. in diameter. This configuration ensures that the frit cannot fall into the beam path and that sample cannot move around the frit. When fouled or clogged, the frit can easily be removed for cleaning or replacement.

\section{Cell temperature control}

Heating cartridges are installed in the cell body and located symmetrically above and below the sample chamber

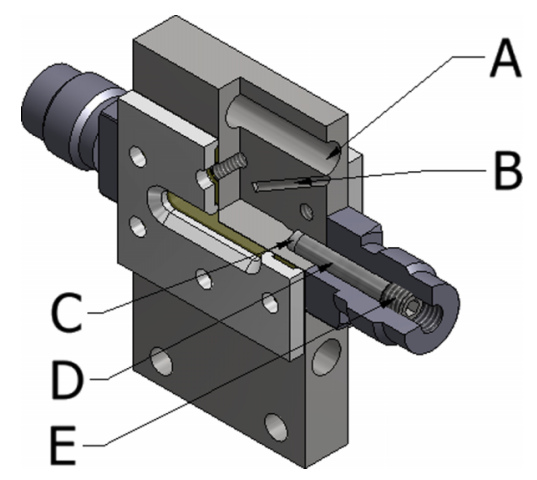

FIG. 3. Cutaway view into the VCR fitting highlighting one half of the sample powder containment. (A) One of the two cutouts for heating cartridges; (B) thermocouple well; (C) stainless steel frit; (D) hollow spacer; (E) hollow set screw.
(Figure 3, A). This configuration ensures nearly even heating around the sample, minimizing temperature gradients. The above-and-below placement of the cartridges also reduces the overall thickness of the cell relative to other designs, maximizing the potential for measuring a fluorescence signal. Although it has not been tested, we suggest that with slight modifications of the cutouts for the heating cartridges, a cold finger could be inserted to cool the sample to sub-ambient temperature, thereby increasing the working temperature range of the cell. Operation of the cell at sub-zero temperatures would require the addition of a dry chamber around the cell to prevent condensation.

A thermocouple to indicate the sample temperature is mounted in a thermowell cut into the cell body (Figure 3, B). This design is in contrast to other designs whereby the thermocouple is placed in the gas or liquid flow path close to or touching the sample. The use of the solid frits prevents a thermocouple mounted in the flow path from coming in contact with the sample. Under vacuum conditions the thermocouple would not register the correct temperature if the thermocouple were mounted near but not touching the sample in the gas flow path. Previous cell designs with the thermocouple mounted in the flow path add complexity to the plumbing and are at high risk of leaks resulting from movement of the cell during transportation.

The thermowell in our cell is cut to hold to a 1/16 in. diameter thermocouple that can be easily added or removed when the cell is installed at the beam line. Because the thermocouple is mounted approximately $2 \mathrm{~mm}$ from the sample and touches the stainless steel body, the sample temperature requires careful calibration. Figure 4 shows a calibration curve generated by controlling the temperature of the cell under static conditions using the thermocouple mounted in the thermowell while the temperature was measured at the center of the cell with a thermocouple inserted into the catalyst bed.

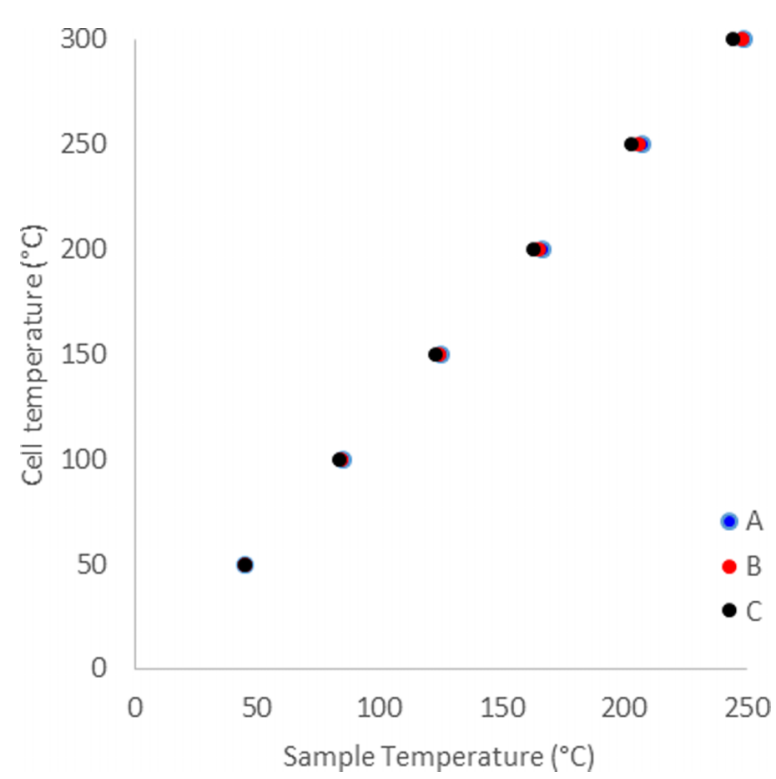

FIG. 4. Calibration curve used for determining controller offsets for the XAS cell with calcium silicate insulation evaluated with 2 blocks of insulation with the cell packed with (A) $\mathrm{MgO}$ and (B) $\mathrm{SiO}_{2}$ and 1 block of insulation with the cell packed with (C) $\mathrm{SiO}_{2}$. 


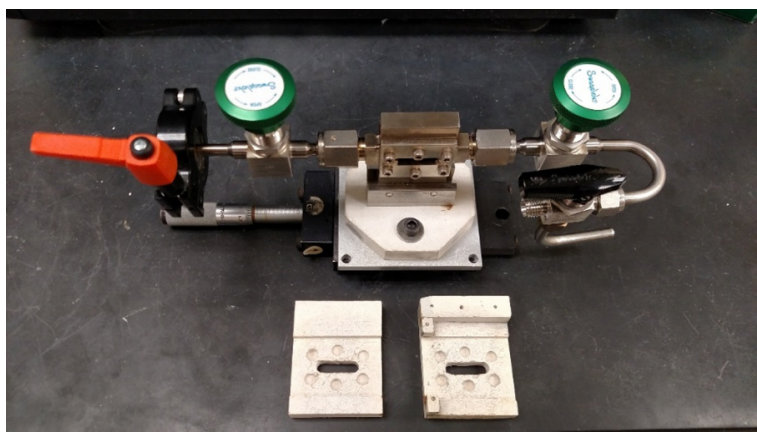

FIG. 5. XAS cell with calcium silicate insulation blocks.

The cell was packed with a characteristic powder sample of $\mathrm{MgO}$ or $\mathrm{SiO}_{2}$ with the cell temperature controlled between 50 and $300{ }^{\circ} \mathrm{C}$ with the sample temperature ranging from 45 to $250^{\circ} \mathrm{C}$. A linear correlation was observed relating these temperatures to each other at equilibrium (Figure 4). The cell was not operated at higher temperatures because of concerns associated with the recommended temperature limit of the Kapton windows.

Calcium silicate insulation is used to cover the cell body at elevated temperatures. Two blocks were machined to encase the cell; both are normally held in place when the cell is used in transmission mode, whereas only one shell is used for fluorescence detection to minimize signal loss (Figure 5). During the temperature calibration testing, it was observed that the calcium silicate blocks improved the temperature stability by reducing noise resulting from drafts in the room, but they did not minimize the temperature offset associated with heat loss.

\section{CELL PERFORMANCE}

To demonstrate both the vacuum and gas flow operation of the cell, it was packed with $600 \mathrm{mg}$ of $40-\mu \mathrm{m}$ diameter particles of $\mathrm{MgO}$, which is representative of a catalyst sample. A maximum helium flow rate of $80 \mathrm{ml} / \mathrm{min}$ was achieved. Dynamic vacuum of $10^{-6}$ Torr was achieved after pumping for 10 min using a turbomolecular pumping station. These values show that the cell performance exceeds the design criteria.

The leak rate of the cell was estimated by infrared monitoring to characterize the adsorption of water on a highly dehydroxylated silica sample (treated at $700{ }^{\circ} \mathrm{C}$ in flowing helium to remove essentially all of the water, as represented schematically in Figure $6^{4}$ ). The cell was packed with the dehydroxylated silica in an argon-filled glove box, sealed and placed under dynamic vacuum; any changes in the infrared spectra representing water-silica interactions would indicate physisorption and/or reaction of water with the surface (Figure 6) and would indicate a leak in the cell. ${ }^{21}$

For benchmarking, we measured infrared spectra of the dehydroxylated silica, observing a sharp band at $3748 \mathrm{~cm}^{-1}$ characteristic of isolated surface $\equiv \mathrm{Si}-\mathrm{OH}$ groups (Figure 7). ${ }^{22}$ A portion of the silica was re-exposed to air/ moisture as a baseline for water adsorption, and an infrared spectrum was collected every $30 \mathrm{~min}$. The spectra show a rapid formation of a broad band centered near $3400 \mathrm{~cm}^{-1}$ (Figure 7)

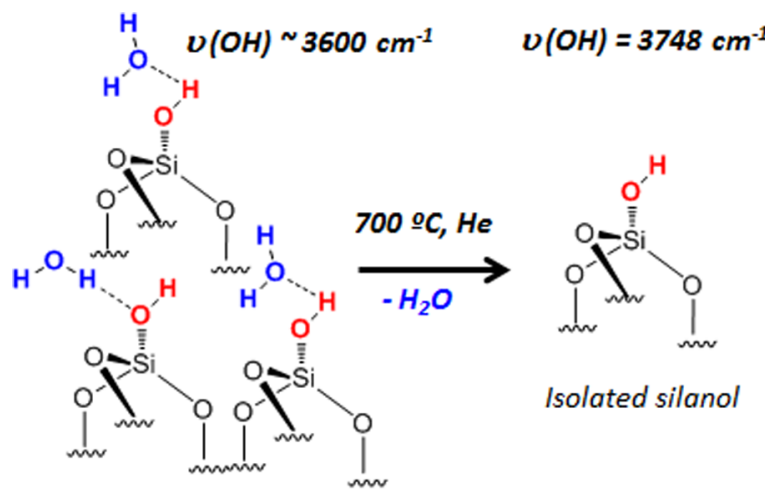

Hydrated silica

Dehydroxylated silica at 700 으

FIG. 6. Water molecule adsorbed by silanol silica surface groups and their corresponding infrared vibration bands $v(\mathrm{OH})$, before and after dehydroxylation.

demonstrating the formation of bridging $\mathrm{OH}$ groups resulting from the water uptake, with saturation of the surface occurring in less than 30 min. ${ }^{23,24}$

Dynamic vacuum $\left(10^{-6}\right.$ Torr $)$ was used to test the leak rate of the cell as a worst-case scenario. Any leak in the cell through or around the windows under vacuum operation conditions would cause water in the ambient air to interact with the highly dehydroxylated silica. The cell was packed in an argon-filled glove box with $250 \mathrm{mg}$ of the treated silica. It was then placed under dynamic vacuum for periods of 1-6 h. The silica was recovered from the cell in a glove box and packed into a sealed infrared cell for analysis. Even after $6 \mathrm{~h}$ of dynamic vacuum, the spectra gave no detectable evidence of a change in the silica, demonstrating the high quality of the window material and the window seal (Figure 7).

The cell's XAS performance was tested at beamline 4-1 at SSRL with both transmission and fluorescence detection. XAS spectra at the Ta $\mathrm{L}_{\mathrm{III}}$ edge $(9881 \mathrm{eV})$ were collected for highly air/moisture sensitive surface organometallic complexes $^{24}$ consisting of tris(neopentyl)(neopentylidene) tantalum (V) supported on amine-modified SBA-1 $15^{25}$ with a tantalum loading of 6 wt. \%. Gas flow rate varied from 3 to $50 \mathrm{~cm}^{3} / \mathrm{min}$, with the gas being helium, $\mathrm{H}_{2}$, or propane, and with the sample temperature ranging from 25 to $250^{\circ} \mathrm{C}$.

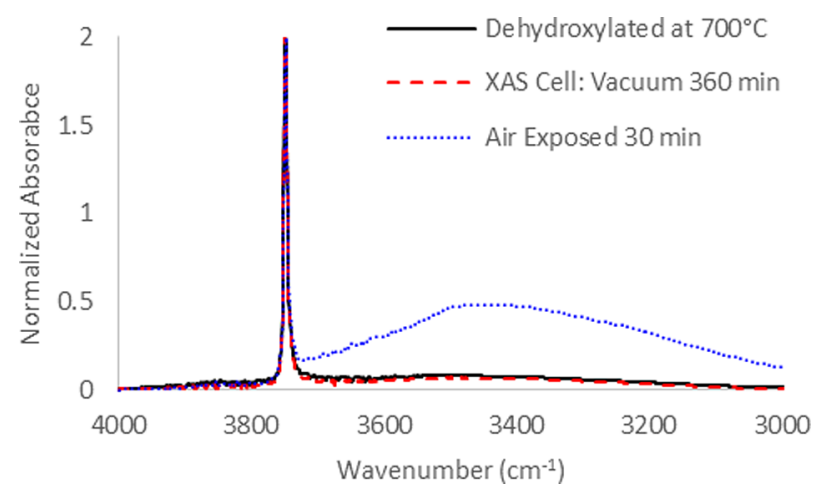

FIG. 7. Normalized infrared spectrum of silica after dehydroxylation at $700{ }^{\circ} \mathrm{C}$ in flowing helium (black); after air/moisture exposure at room temperature for $30 \mathrm{~min}$ (blue); and after dynamic vacuum $\left(10^{-6}\right.$ Torr) for $360 \mathrm{~min}$ as packing in the XAS cell (red). 

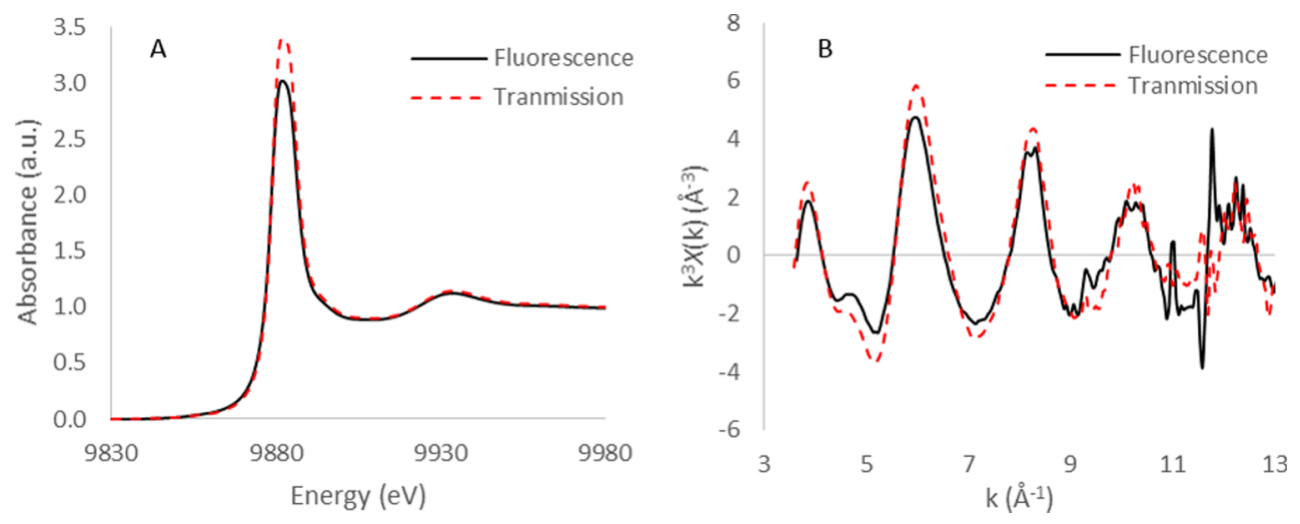

FIG. 8. Normalized XANES data (a) and $k^{3}$-weighted EXAFS functions (b), obtained from the Ta $\mathrm{L}_{\text {III }}$ XAS transmission and fluorescence spectra characterizing tris(neopentyl)(neopentylidene) tantalum (V) supported on amine-modified SBA-15 at a Ta loading of 6 wt. \%; see the text for details. These results provide a comparison of the spectra collected simultaneously with fluorescence and transmission detection.

Transmission data were collected with nitrogen-filled ion chambers. Fluorescence data were collected using Soller slits to reduce random beam scattering and a PIPS detector.

Figure 8 shows the extended X-ray absorption fine structure (EXAFS) function extracted from the Ta $\mathrm{L}_{\mathrm{III}}$ absorption and fluorescence spectra characterizing the catalyst at $150^{\circ} \mathrm{C}$ with the sample in flowing helium. The spectra collected simultaneously in these modes are nearly identical, deviating at approximately $k=12 \AA^{-1}$ ( $k$ is the wave vector) because of a glitch in the monochromator that is more evident in the fluorescence signal than in the transmission signal. The results demonstrate the successful operation of the cell as a transmission and fluorescence flow cell capable of operating at $250{ }^{\circ} \mathrm{C}$.

\section{ADVANTAGES AND DISADVANTAGES OF THE CELL DESIGN}

The cell design reported here offers a number of advantages relative to other cells used for XAS. The design allows for operation under high vacuum or with gas flowing through a bed of the sample. Sample temperature can be safely controlled up to $300{ }^{\circ} \mathrm{C}$ with the ability for modifications to increase the limit. The flow through the cell ensures that a large fraction of the sample is exposed to the reactive atmosphere. The narrowness of the cell permits its mounting for simultaneous detection in transmission and fluorescence modes. The small size of the cell allows for rapid transfer in and out of glove boxes. The sample body and inlet/outlet plumbing can be customized to specific synchrotron sources and experimental conditions.

Nonetheless, there are some limitations to the design. The fact that the thermocouple does not directly touch the sample requires tedious calibration and care during installation to ensure that the thermocouple is in contact with the bottom of the thermowell. The press seal window design brings some challenges, requiring that close attention be paid to (1) avoiding marring of the surface of the cell and (2) effectively sealing the windows for vacuum operation. Close attention must be paid to the possibility of leaks. The construction with stainless steel and vacuum-rated plumbing makes the cell more expensive than some other designs, with a typical cost estimated to be in the range of $\$ 4000-\$ 6000$ per cell, depending on the number of cells being made. The stainless steel also contains heavier absorbing elements such as $\mathrm{Mn}, \mathrm{Cr}, \mathrm{Ni}, \mathrm{Mo}$, and Fe which are often found in catalyst samples but are not found in aluminum. During fluorescence experiments at energies above the edges of the elements in the stainless steel, this fluorescence signal may interfere with the fluorescence signal of the sample.

\section{v. CONCLUSIONS}

We have designed and fabricated a robust XAS cell for powder samples capable of transmission and fluorescence detection modes while operating under dynamic vacuum or in reactive atmospheres at room temperature or elevated temperatures. New design features that set the cell apart from the rest are (1) press-seal polyimide windows that allow for vacuum operation without the use of O-rings; (2) stainless steel frits for powder stabilization during large pressure swings instead of glass/quartz wool; (3) a small cell thickness that allows for simultaneous transmission and fluorescence detection while achieving a high gas-sample interaction rate mimicking a plug flow design.

\section{ACKNOWLEDGMENTS}

We thank A. Cobb and J. Roach of the University of California, Davis, Biological and Agricultural Engineering Machine Shop, for design consultation and cell fabrication, and R. Davis of the Stanford Synchrotron Radiation Lightsource (SSRL) for helpful discussions. We thank SSRL for beam time (beamline 4-1). The work was funded by the King Abdullah University of Science and Technology and by the U.S. Department of Energy, Office of Science, Basic Energy Sciences (Grant No. FG02-04ER15513). Use of SSRL, SLAC National Accelerator Laboratory, is supported by the U.S. Department of Energy, Office of Science, Basic Energy Sciences (Grant No. DE-AC02-76SF00515). A. S. Hoffman was supported by a fellowship from Chevron.

\footnotetext{
${ }^{1} X$-Ray Absorption and X-Ray Emission Spectroscopy: Theory and Applications, edited by J. A. van Bokhoven and C. Lamberti (Wiley, Chichester, 2016).

${ }^{2} X$-Ray Absorption: Principles, Applications, Techniques of EXAFS, SEXAFS and XANES, edited by D. C. Koningsberger and R. Prins (Wiley, New York, 1987).

${ }^{3}$ I. Ogino, P. Serna, and B. C. Gates, in Handbook of Solid State Chemistry, edited by R. Dronskowski, S. Kikkawa, and A. Stein (Wiley, in press).
} 
${ }^{4}$ N. Maity, S. Barman, E. Callens, M. K. Samantaray, E. Abou-Hamad, Y. Minekov, V. D'elia, A. S. Hoffman, C. M. Widdifield, L. Cavallo, B. C. Gates, and J.-M. Basset, Chem. Sci. 7, 1558 (2016).

${ }^{5}$ B. Qiao, A. Wang, X. Yang, L. F. Allard, Z. Jiang, Y. Cui, J. Liu, and T. Zhang, Nat. Chem. 3, 634 (2011).

${ }^{6}$ C. Martinez-Macias, M. Chen, D. A. Dixon, and B. C. Gates, Chem. Eur. J. 21, 11825 (2015)

${ }^{7}$ S. Soled, Science 350, 1171 (2015); D. C. Koningsberger, B. L. Mojet, G. E. van Dorssen, and D. E. Ramaker, Top. Catal. 10, 143 (2000).

${ }^{8}$ R. E. Jentoft, S. E. Deutsch, and B. C. Gates, Rev. Sci. Instrum. 67, 2111 (1996).

${ }^{9}$ J. F. Odzak, A. M. Argo, F. S. Lai, B. C. Gates, K. Pandya, and L. Feraria, Rev. Sci. Instrum. 72, 3943 (2001).

${ }^{10}$ N. Weiher, E. Bus, B. Gorzolnik, M. Möller, R. Prins, and J. A. van Bokhoven, J. Synchrotron Radiat. 5, 675 (2005).

${ }^{11}$ S. R. Bare and R. Thorsten, Adv. Catal. 52, 339 (2009).

${ }^{12}$ F. W. Lytle, P. S. P. Wei, R. B. Greegor, G. H. Via, and J. H. Sinfelt, J. Chem. Phys. 70, 4849 (1979).

${ }^{13}$ R. Revel, D. Bazin, A. Seigneurin, P. Barthe, J. M. Dubuisson, T. Decamps, H. Sonneville, J. J. Poher, F. Maire, and P. Lefrancois, Nucl. Instrum. Methods Phys. Res., Sect. B 155, 183 (1999).
${ }^{14}$ R. A. Dalla Betta, M. Boudart, K. Fogler, D. G. Loffler, and J. Sanchezarrieta, Rev. Sci. Instrum. 55, 1910 (1984).

${ }^{15}$ T. L. Neils and J. M. Burlitch, J. Catal. 118, 79 (1989).

${ }^{16}$ F. W. H. Kampers, T. M. J. Maas, J. van Grondelle, P. Brinkgreve, and D. C. Koningsberger, Rev. Sci. Instrum. 60, 2635 (1989).

${ }^{17}$ D. G. Castner, P. R. Watson, and I. Y. Chan, J. Phys. Chem. 94, 819 (1990).

${ }^{18}$ K. Asakura and Y. Iwasawa, J. Phys. Chem. 93, 4213 (1989).

${ }^{19}$ S. Hannemann, M. Casapu, J. D. Grunwalds, P. Haider, P. Trussel, A. Baiker, and E. Welter, J. Synchrotron Radiat. 14, 345 (2007).

${ }^{20}$ See supplementary material at http://dx.doi.org/10.1063/1.4958824 for a full set of blueprints summarizing cell fabrication and assembly.

${ }^{21}$ L. T. Zhuravlev, Colloids Surf., A 173, 1 (2000).

${ }^{22}$ B. A. Morrow, in Surface Groups on Oxides, Part A (Elservier, New York, 1990), Vol. 57, Chap. III, pp. A161-A224.

${ }^{23}$ K. M. Davis and M. Tomozawa, J. Non-Cryst. Solids 201, 177 (1996).

${ }^{24}$ Modern Surface Organometallic Chemistry, edited by J.-M. Basset, R. Psaro, D. Roberto, and R. Ugo (Wiley, New York, 2009).

${ }^{25}$ A. Bendjeriou-Sedjerari, J. M. Azzi, E. Abou-Hamad, D. H. Anjum, F. A. Pasha, K.-W. Huang, L. Emsley, and J.-M. Basset, J. Am. Chem. Soc. 135, 17943 (2013). 